Pesq. Vet. Bras. 37(3):248-256, março 2017

DOI: $10.1590 / \mathrm{S} 0100-736 \mathrm{X} 2017000300008$

\title{
Caracterização clínica e histopatológica das dermatites alérgicas em cães ${ }^{1}$
}

\author{
Jackson S. de Vasconcelos ${ }^{2 *}$, Temístocles S. de Oliveira Neto², Harlan H.L. \\ Nascimento ${ }^{3}$, Francisca M.S. Barbosa ${ }^{3}$, Fábbio Ygor S. Rezende ${ }^{4}$, Lindemarques \\ G. de Oliveira ${ }^{5}$, Ricardo B. Lucena ${ }^{3}$ e Antônio F.M. Dantas ${ }^{2}$
}

\begin{abstract}
Vasconcelos J.S., Oliveira Neto T.S., Nascimento H.H.L., Barbosa F.M.S., Rezende F.Y.S, Oliveira L.G., Lucena R.B. \& Dantas A.F.M. 2017. [Clinical and histopathological characterization of allergic dermatitis in dogs.] Caracterização clínica e histopatológica das dermatites alérgicas em cães. Pesquisa Veterinária Brasileira 37(3):248-256. Programa de Pós-Graduação em Medicina Veterinária, Universidade Federal de Campina Grande, Centro de Saúde e Tecnologia Rural, Campus Patos, Av. Universitária s/n, Bairro Santa Cecília. Cx. Postal 61, Patos, PB 58708-110, Brazil. E-mail: veterinariojsv@yahoo.com.br

This paper describes the clinical and histopathological features of allergic dermatitis in dogs diagnosed the metropolitan region of João Pessoa, Paraíba. From September 2014 to September 2015 a total of 90 dogs with skin lesions was studied. Twenty-four cases showed changes consistent with allergic dermatitis, in 12 males and 12 females. The age of dogs ranged from 3 months to 15 years. Atopic dermatitis was the most common, affecting $58.33 \%(14 / 24)$ of the dogs, followed by food hypersensitivity dermatitis at $25 \%(6 / 24)$, allergic contact dermatitis at $8.33 \%(2 / 24)$, a case of allergic dermatitis flea and one case of drug hypersensitivity, which represented $4.17 \%$ respectively. Gross lesions included hypotrichosis, hyperpigmentation, comedones, erythema, alopecia, xerosis, erosions, ulcers, and exudates. Anatomically distributed was on face, head, neck, thoracolumbar, lumbosacral, flank, limbs and abdomen. The most common microscopic lesions were hyperkeratosis, acanthosis, spongiosis and exocytosis of lymphocytes in the epidermis. In the superficial dermis was observed perivasculitis, perianexite and in some cases pigmentary incontinence, edema, dilated lymphatic vessels and sweat glands. Histopathological examination associated with medical history, clinical examination and skin examen are important tools for the diagnosis of allergic dermatitis in dogs, as well as for associated therapeutic measures.

INDEX TERMS: Dermatitis, dogs, skin diseases, hypersensitivity.
\end{abstract}

RESUMO.- Descrevem-se as características clínicas e histopatológicas da dermatite alérgica diagnosticada em cães da região metropolitana de João Pessoa, Paraíba. Durante o período de setembro de 2014 a setembro de 2015, um total

\footnotetext{
${ }^{1}$ Recebido em 27 de fevereiro de 2016.

Aceito para publicação em 29 de julho de 2016.

${ }^{2}$ Programa de Pós-Graduação em Medicina Veterinária, Hospital Veterinário, Av. Universitária s/n, Bairro Santa Cecília, Cx. Postal 64, Patos, PB 58708-110, Brasil. *Autor para correspondência: veterinariojsv@ yahoo.com.br

${ }^{3}$ Departamento de Ciências Veterinárias, Centro de Ciências Agrárias, Universidade Federal da Paraíba (UFPB), Rodovia PB-079, Areia, PB 58397-000, Brasil.

${ }^{4}$ Médico Veterinário autônomo, Av. Monteiro da Franca 1149, Manaíra, João Pessoa, PB 58038-320, Brasil.

${ }^{5}$ Médico Veterinário autônomo, Rua Severino Antônio de Sousa 164, Mangabeira, João Pessoa, PB 58055-410, Brasil.
}

de 90 cães com lesões cutâneas. Desses 24 apresentaram alterações compatíveis com dermatite alérgica, sendo 12 machos e 12 fêmeas. A dermatite atópica (DA) foi a mais frequente, afetando 58,33\% (14/24) dos cães, seguido por dermatite por hipersensibilidade alimentar (HA) 25\% (6/24), dermatite de contato alérgica (DAC) com 8,33\% $(2 / 24)$ dos casos, dermatite alérgica por picada de pulgas (DAPP) com um caso e a hipersensibilidade a medicamento (farmacodermia) também um caso, que representou $4,17 \%$ respectivamente. As lesões macroscópicas incluíram hipotricose, hiperpigmentação, comedões, eritema, alopecia, xerose, erosões, úlceras e exsudato, anatomicamente distribuídas na face, cabeça, pescoço, toracolombar, lombossacra, flanco, membros e abdome. As lesões microscópicas mais frequentes foram hiperceratose, acantose, espongiose e exocitose de linfócitos na epiderme. Na derme superficial 
foi observada perivasculite, perianexite e em alguns casos de incontinência pigmentar, edema, dilatação de vasos sanguíneos, linfáticos e glândulas sudoríparas. 0 exame histopatológico associado com a história clínica, exame clínico e pele são ferramentas importantes para o diagnóstico de dermatite alérgica em cães, bem como medidas terapêuticas associadas.

TERMOS DE INDEXAÇÃO: Dermatite, caninos, dermatopatias, hipersensibilidade.

\section{INTRODUÇÃO}

Dentre as doenças de pele, as dermatites alérgicas são as mais frequentes em cães, tanto na rotina diagnóstica de biópsias de pele (Souza et al. 2009), quanto na revisão de prontuários de atendimento clínico ambulatorial (Cardoso et al. 2011, Gasparetto et al. 2013). Essas doenças caracterizam-se por inflamação crônica da pele, acompanhada de prurido e afetam humanos e animais de companhia, especialmente os cães (Leung 1995, Scott et al. 2001).

As doenças alérgicas da pele de cães podem ter causas diversas e apresentar formas clínicas variadas como placas liquenificadas, e nódulos (Marsella \& Olivry 2001), além das lesões auto-traumáticas induzidas pelo prurido (Scott et al. 2001). Essa diversidade de apresentações clínicas dificulta o diagnóstico clínico. Para chegar a um diagnóstico dermatológico definitivo ou diferencial de dermatite alérgica é necessário realizar anamnese detalhada e exame físico minucioso, junto a métodos diagnósticos rotineiros como raspados de pele, exame micológico direto, tricograma, exame citológico, cultura fúngica e bacteriana (Souza et al. 2009, Medleau \& Hnilica 2009). No entanto, os exames complementares podem não serem suficientes para o diagnóstico e nesses casos o clínico deve recorrer a biópsias e exames histopatológicos (Conceição et al. 2004).

As doenças dermatológicas alérgicas mais comuns incluem a dermatite alérgica à picada de pulgas (DAPP), a dermatite atópica (DA), a hipersensibilidade alimentar (HA) e a dermatite alérgica de contato (DAC). A DAPP caracteriza-se por ser uma doença alérgica pruriginosa, em que as lesões, nos cães, localizam-se com maior frequência na região lombossacra, dorsocaudal, na base da cauda, períneo e na face caudomedial das coxas (Hargis \& Ginn 2013). No exame histopatológico predomina infiltrado de eosinófilos e células mononucleares na derme superficial (Gross et al. 2005). A DA é uma doença inflamatória e pruriginosa da derme, predisposta geneticamente (Halliwell 2009). A face, focinho, carpos, extremidades distais, orelhas e as regiões ventrais são as áreas mais acometidas nos cães, e caracterizam-se histologicamente por discreta inflamação mononuclear perivascular na derme superficial (Gross et al. 2005).

A HA é uma doença pruriginosa localizada ou generalizada, não sazonal, que normalmente acomete orelhas, membros, região axilar ou inguinal, face, pescoço e períneo, provocando eritema e outras lesões como erupção papular e lesões secundárias por automutilação (Medleau \& Hnilica 2009, Hargis \& Ginn 2013), com inflamação geralmente severa na derme que pode variar de focal a multifocal
(Gross et al. 2005). A DAC caracteriza-se por uma reação de contato prolongado do alérgeno envolvido com a pele, que pode ser uma substância que não causa reação imediata, mas tardiamente (Medleau \& Hnilica 2009). A reação de hipersensibilidade é do tipo IV, sendo desencadeada pelo contato da pele dos cães ao alérgeno, resultando em uma inflamação crônica (Gross et al. 2005). Torna-se necessário a realização de um estudo para se conhecer os aspectos clínicos e patológicos com o intuito de auxiliar os clínicos nos diagnósticos destas dermatopatias.

0 presente trabalho teve por objetivo descrever os aspectos clínicos e histopatológicos das dermatites alérgicas em cães atendidos em clínicas veterinárias.

\section{MATERIAL E MÉTODOS}

Foram acompanhados os atendimentos dermatológicos de cães em três clínicas veterinárias, sendo duas localizadas em João Pessoa e uma em Bayeux, pertencente à região metropolitana de João Pessoa, Estado da Paraíba, no período de setembro de 2014 a setembro de 2015. Para o levantamento dos dados clínicos e dermatológicos foi utilizada uma ficha dermatológica adaptada de Souza et al. (2009) e realizado exame clínico completo e dermatológico. Todos os cães com lesões cutâneas foram submetidos a exames dermatológicos (citológicos, raspado de pele, parasitológico, tricograma, bacteriológico, micológico e histopatológico. Os diagnósticos clínicos dermatológicos foram estabelecidos seguindo os critérios e padrões já descritos (Gross et al. 2005, Medleau \& Hnilica 2009, Hargis \& Ginn 2013).

As biópsia de pele, foram obtidas após os cães terem sidos sedados com xilazina $2 \%$ na dose de $0,5 \mathrm{mg} / \mathrm{kg} / \mathrm{pv}$, cetamina a 10 $\%$ na dose de $10 \mathrm{mg} / \mathrm{kg} / \mathrm{pv}$ e lidocaína a $2 \%$ na dose de $7 \mathrm{mg} / \mathrm{kg} /$ pv. Todas as biópsias foram incisionais, dando-se preferência aos sítios onde se encontravam mais lesões primárias e não tratadas, como máculas, pápulas, vesículas, pústulas e vergões. Nos casos em que o animal não apresentava mais lesões primárias, foram colhidas amostras das lesões secundárias como escamas, crostas, úlceras, comedões e escaras (Hargis \& Ginn 2013). As amostras colhidas para o exame histopatológico foram fixadas em solução de formalina a $10 \%$, processadas rotineiramente para histologia e coradas pela hematoxilina-eosina (HE).

O diagnóstico de dermatite alérgica foi realizado com base no histórico clínico, nos exames dermatológicos, resultados de exames laboratoriais complementares (hemograma e bioquímicas séricas), histopatológicos e em alguns casos no acompanhamento durante o tratamento.

\section{RESULTADOS}

No período de setembro de 2014 a setembro de 2015 foram atendidos 596 cães, sendo 299 (50,2\%) machos e 297 (49,8\%) fêmeas. Destes 152 (25,5\%) apresentaram lesão dermatológica, dos quais, 90 foram submetidos à biópsia de pele, onde $24(15,79 \%)$ tiveram diagnóstico de dermatite alérgica, destes 12 eram machos e 12 fêmeas. Dezesseis tinha raça definida, oito eram sem raça definida (SRD) e a idade variou de três meses a 15 anos, com média de 5,8 anos. Os dados referentes a raça, sexo, idade e o diagnóstico das dermatites alérgicas foram descritos no quadro 1.

As lesões macroscópicas observadas foram agrupadas no quadro 2, de acordo com o tipo da lesão e a localização, tomando-se como base Hargis \& Ginn (2013). Em todos os casos foram frequentes as lesões crônicas, caracterizadas 
por hipotricose, alopecia, máculas, erosões e úlceras, sempre acompanhadas por prurido. Em nenhum caso foi descrito histórico de prurido sazonal. As lesões microscópicas foram agrupadas no quadro 3, de acordo com a localização anatômica específica para a epiderme, derme superficial e profunda (Gross et al. 2005).

A dermatite atópica foi a mais frequente, diagnosticada em 58,33\% (14/24) dos cães acometidos por dermatite alérgica, sendo oito machos e seis fêmeas, com idade variando entre três meses e oito anos de idade. As raças acometidas foram Pitbull, Pinscher, Labrador e SRD com dois casos cada. Com um caso foram acometidas as raças Poodle, Cocker Spaniel, Pastor Alemão, Pug, Teckel e Labrador. Dos cães com DA, três tiveram infecção bacteriana secun-

Quadro 1. Relação de raça, sexo e idade dos cães com dermatites alérgicas diagnosticadas na região metropolitana de João Pessoa, Paraíba

\begin{tabular}{ccccc}
\hline Caso no. & Sexo & Raça & Idade & Diagnóstico \\
\hline 01 & F & SRD & 10 anos & Hipersensibilidade alimentar \\
02 & F & Akita & 9 anos & Hipersensibilidade alimentar \\
03 & F & Poodle & 5 anos & Dermatite atópica \\
04 & M & Labrador & 6 anos & Dermatite atópica \\
05 & F & Pitbul & 5 anos & Dermatite atópica \\
06 & F & Pitbul & 6 anos & Dermatite atópica \\
07 & F & Pinscher & 5 anos & Dermatite atópica \\
08 & F & B. Francês & 1,4 anos & Hipersensibilidade \\
& & & & a sulfametoxazol \\
09 & M & Cocker & 3 anos & Dermatite atópica \\
10 & M & P. Alemão & 3 meses & Dermatite atópica \\
11 & M & Pug & 2 anos & Dermatite atópica \\
12 & M & Pinscher & 6 anos & Dermatite atópica \\
13 & F & SRD & 4 meses & Dermatite atópica \\
14 & M & Teckel & 8 anos & Dermatite atópica \\
15 & M & SRD & 8 anos & Dermatite alérgica de contato \\
16 & M & SRD & 10 anos & Hipersensibilidade alimentar \\
17 & F & SRD & 9 anos & Dermatite alérgica de contato \\
18 & M & P. Alemão & 15 anos & Dermatite alérgica \\
& & & & a picada de pulgas \\
19 & F & SRD & 5 anos & Dermatite atópica \\
20 & M & Labrador & 2 anos & Hipersensibilidade alimentar \\
21 & M & Golden & 3 anos & Dermatite atópica \\
22 & F & SRD & 3 anos & Hipersensibilidade alimentar \\
24 & F & SRD & 5 anos & Hipersensibilidade alimentar \\
& Labrador & 3 anos & Dermatite atópica \\
\hline
\end{tabular}

$\overline{\mathrm{F}}=$ Fêmea, $\mathrm{M}=$ macho, $\mathrm{SRD}=$ sem raça definida. dária por Staphyloccus aureus, dois por Demodex canis e um por Malassezia pachydermatis.

As lesões macroscópicas da DA consistiram em erosões $64,29 \%(9 / 14)$, comedões $57,14 \%(8 / 14)$, hipotricose $50 \%(7 / 14)$, colaretes epidérmicos $50 \%(7 / 14)$, crostas 42,86\% (6/14), máculas 35,71\% (5/14), descamação $35,71 \%(5 / 14)$, alopecia $35,71 \%(5 / 14)$, seborreia $28,6 \%$ (4/14), xerose cutânea $21,43 \%$ (3/14). pápulas $21,43 \%$ (3/14), pústulas $14,3 \%(2 / 14)$, hiperpigmentação $14,23 \%$ (2/14), eritema 7,14\% (1/14), escoriações 7,14\% (1/14), úlceras 7,14 (1/14), exsudato 7,14\% (1/14) e hipopigmentação $7,14 \%(1 / 14)$.

As lesões da DA ocorreram em diferentes sítios anatômicos como região lombossacra $57,14 \%(8 / 14)$, toracolombar 57,14\% (8/14), abdominal 42,86\% (6/14), axilar $35,71 \%(5 / 14)$, cabeça $35,71 \%(5 / 14)$, membros toráci$\cos 21,42 \%(3 / 14)$, região cervical 21,42\% (3/14), flancos $21,42 \%$ (3/14), região sacral 14,29\% (2/14), região perineal 14,29\% (2/14), membros pélvicos 7,14\% (1/14) e o pavilhão auricular 7,14\% (1/14) (Fig.1A,B). As lesões microscópicas observadas foram hiperceratose 100\% (14/14) variando de leve a acentuada; acantose $100 \%(14 / 14)$ de leve a moderada; espongiose $100 \%(14 / 14)$ de leve a acentuada; exocitose de linfócitos na epiderme 35,71\% (5/14) de leve a moderada; pústulas 28,57\% (4/14) de leve a acentuada; úlceras $21,42 \%(3 / 14)$ de leve a acentuada e acantólise moderada $7,14 \%(1 / 14)$. Na derme havia perivasculite em $100 \%$ (14/14) de leve a acentuada; perianexite $85,71 \%$ $(12 / 14)$ de leve a acentuada, edema 78,57\% (11/14) de leve a acentuado, moderada dilatação de vasos linfáticos $35,71 \%$ (5/14), incontinência pigmentar 28,57\% (4/14) leve e dilatação da glândula sudorípara 14,23\% (2/14) de leve a moderada. Em todos os casos de DA foi observado infiltrado inflamatório de células mononucleares (Fig.2A,B). Nos casos de infecções bacterianas secundárias, foi adotada terapia com cefalexina na dose de $30 \mathrm{mg} \mathrm{kg} / \mathrm{pv}$ a cada 12 horas por 10 dias. Nas infecções por fungos foi instituído terapia a base de itraconazol na dose de $5 \mathrm{mg} / \mathrm{kg} / \mathrm{pv}$ a cada 24 horas por 30 dias. 0 tratamento específico para DA foi realizado usando-se corticoterapia a base de predinisolona na dose de $1 \mathrm{mg} / \mathrm{kg} / \mathrm{pv}$ a cada 24 horas durante 10 dias. Em um caso foi necessário o uso de ciclosporina na dose

\section{Quadro 2. Lesões macroscópicas e localizações anatômicas das dermatites alérgicas diagnosticadas em cães na região} metropolitana de João Pessoa, Paraíba

\begin{tabular}{|c|c|c|c|}
\hline Diagnóstico & № de casos & Lesões macroscópicas & Localização anatômica \\
\hline Dermatite atópica & 14 & $\begin{array}{l}\text { Hipotricose, alopecia, comedões, colaretes epidérmicos, } \\
\text { xerose, erosões, mácula, descamação, hiperpigmentação, } \\
\text { hipopigmentação, escoriações, crostas, úlceras, } \\
\text { exsudato, pápulas, pústulas e seborreia }\end{array}$ & $\begin{array}{l}\text { Regiões lombossacra, perineal, toracolombar, } \\
\text { axilares e dorsais. } \\
\text { Na cabeça, pavilhão auricular, abdome, } \\
\text { membros torácicos e pélvicos e flancos }\end{array}$ \\
\hline Hipersensibilidade alimentar & 06 & $\begin{array}{l}\text { Hipotricose, alopecia, hiperpigmentação, } \\
\text { comedões, erosões, máculas, escoriações, } \\
\text { colaretes epidérmicos, eritema, } \\
\text { descamação e úlceras com exsudação }\end{array}$ & $\begin{array}{l}\text { Cabeça, pavilhão auricular, região periocular, } \\
\text { abdome, regiões axilares, toracodorsal, } \\
\text { toracolombar pré-escapular, lombossacra, } \\
\text { cervical, membros pélvicos e flancos }\end{array}$ \\
\hline $\begin{array}{l}\text { Dermatite alérgica a picada } \\
\text { de pulgas }\end{array}$ & 01 & $\begin{array}{l}\text { Alopecia, hiperpigmentação, máculas, } \\
\text { úlceras com exsudação }\end{array}$ & Região lombossacra \\
\hline Hipersensibilidade a & 01 & Alopecia, erosões e úlceras & Região toracolombar \\
\hline
\end{tabular}

sulfametoxazol 
Quadro 3. Distribuição das lesões microscópicas observadas nas dermatites alérgicas de cães na região metropolitana de João Pessoa, Paraíba

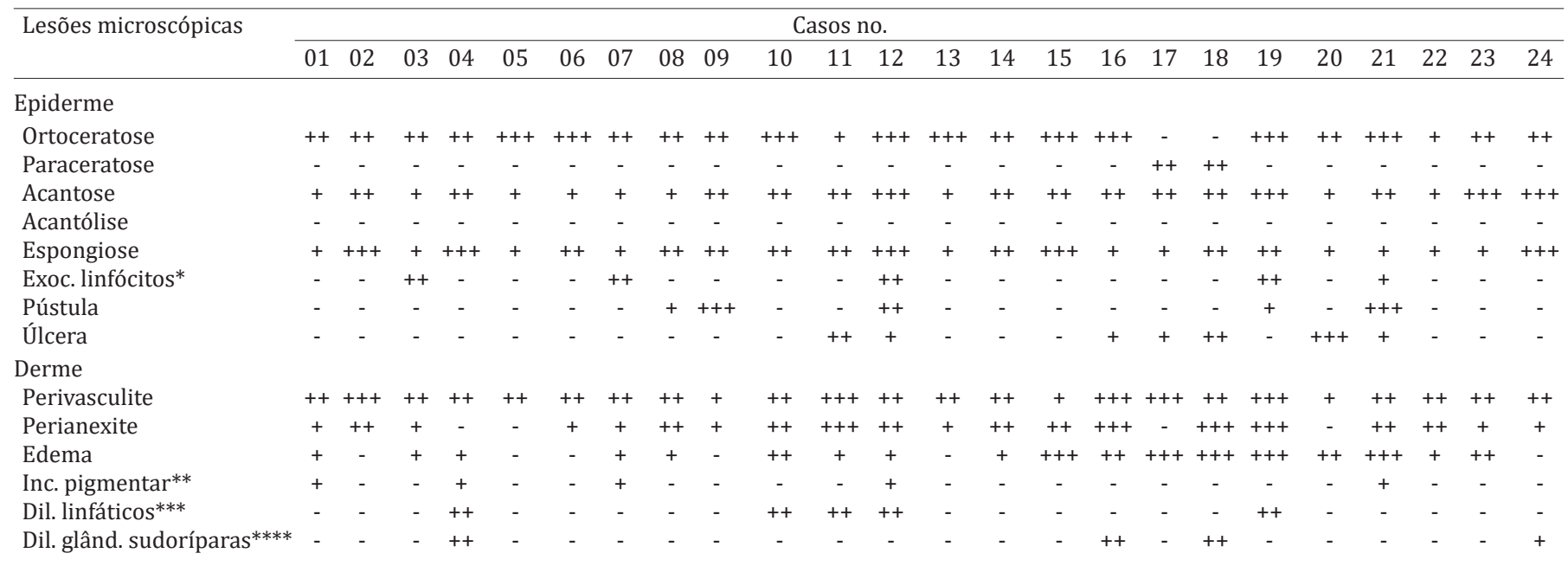

+ Leve, ++ moderada, +++ acentuada, - não observado. * Exoc. de linfócitos, ${ }^{* *}$ Incontinência pigmentar, *** Dilatação de vasos linfáticos, **** Dilatação de glândulas sudoríparas.
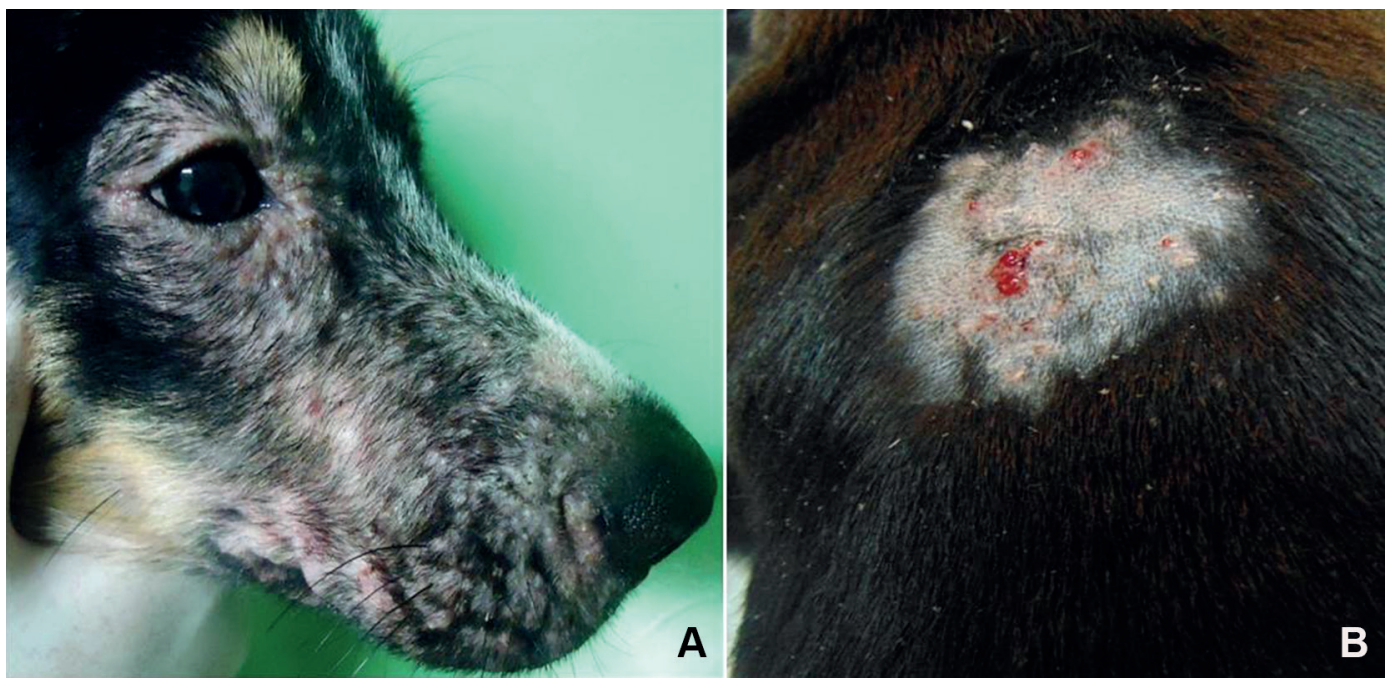

Fig.1. Dermatite atópica canina. Pele. (A) Hipotricose e alopecia na face, principalmente nas regiões nasal e periocular. (B) Pústula e hemorragia na região toracolombar.

de $5 \mathrm{mg} / \mathrm{kg} / \mathrm{pv}$ a cada 24 horas por tempo indeterminado. Para todos os casos foi recomendado o uso de nutracêutico a base de ômega $3^{6}$, com o objetivo de diminuir a xerose dérmica e desempenhar efeito anti-inflamatório.

A hipersensibilidade alimentar representou 25\% (6/24) dos casos de dermatites alérgicas estudadas, sendo quatro fêmeas e dois machos, a idade variou de dois anos a dez anos de idade. As raças acometidas foram SRD com quatro casos, Akita e Labrador um caso cada. 0 exame clínico dermatológico evidenciou prurido localizado não sazonal, ferimentos secundários ao prurido, áreas hipotricóicas, áreas alopécicas. Três cães eram alimentados com comida caseira e ração comercial e os demais recebiam somente ração comercial. As lesões macroscópicas caracterizaram-se por erosões $100 \%(6 / 6)$, hipotricose $66,66 \%$ (4/6), máculas $50 \%(3 / 6)$, comedões 50\% (3/6), eritema 33,33\% (2/6), alopecia $33,33 \%(2 / 6)$, escoriações $33,33 \%(2 / 6)$, hiperpigmentação $33,33 \%$ (2/6), colaretes epidérmicos $16,66 \%$
(1/6); descamação 16,66\% (1/6), úlceras 16,66\% (1/6) e exsudação 16,66\% (1/6). As localizações mais frequentes das lesões foram nos flancos $50 \%(3 / 6)$; cabeça $33,33 \%$ $(2 / 6)$, membros torácicos $33,33 \%(2 / 6)$, região toracolombar 33,33\% (2/6), região lombossacra 33,33\% (2/6), abdome $16,66 \%$ (1/6), região axilar 16,66\% (1/6), região toracodorsal $16,66 \%(1 / 6)$, região pré-escapular $16,66 \%$ $(1 / 6)$, região cervical $16,66 \%(1 / 6)$ e no pavilhão auricular $16,66 \%(1 / 6)$.

As lesões microscópicas da HÁ na epiderme caracterizaram-se por hiperceratose $100 \%(6 / 6)$ que variou de leve a acentuada; acantose $100 \%(6 / 6)$ de leve a moderada; espongiose $100 \%(6 / 6)$ de leve a acentuada e úlceras 33,33\% $(2 / 6)$ de leve a acentuada. Na derme foi observado perivasculite $100 \%(6 / 6)$ de leve a acentuada; perianexite 83,33\% (5/6) de leve a acentuada; edema 83,33\% (5/6) de leve a moderado; leve incontinência pigmentar de 16,66\% (1/6) e dilatação de vasos linfáticos 16,66\% (1/6) leve. Foi obser- 


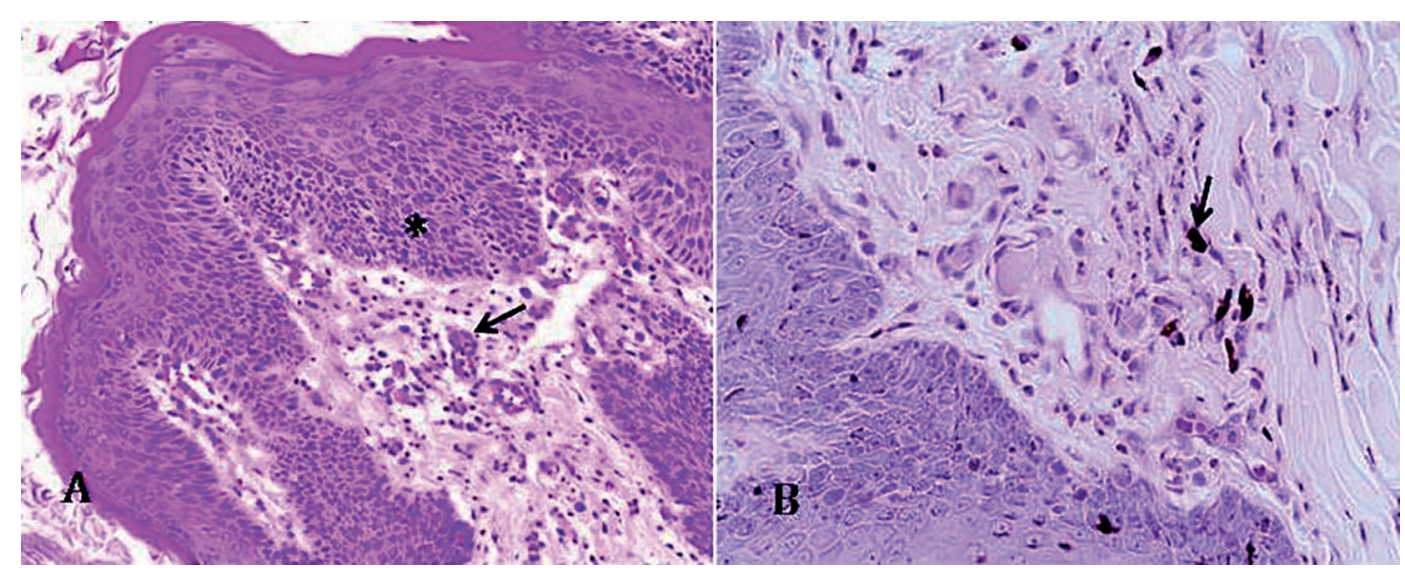

Fig.2. Dermatite atópica canina. Pele. (A) Observa-se espongiose (asterisco) e infiltrado mononuclear ao redor de vasos (seta). HE, obj.20x. (B) observa-se incontinência pigmentar na derme superficial (seta). HE, obj.40x.

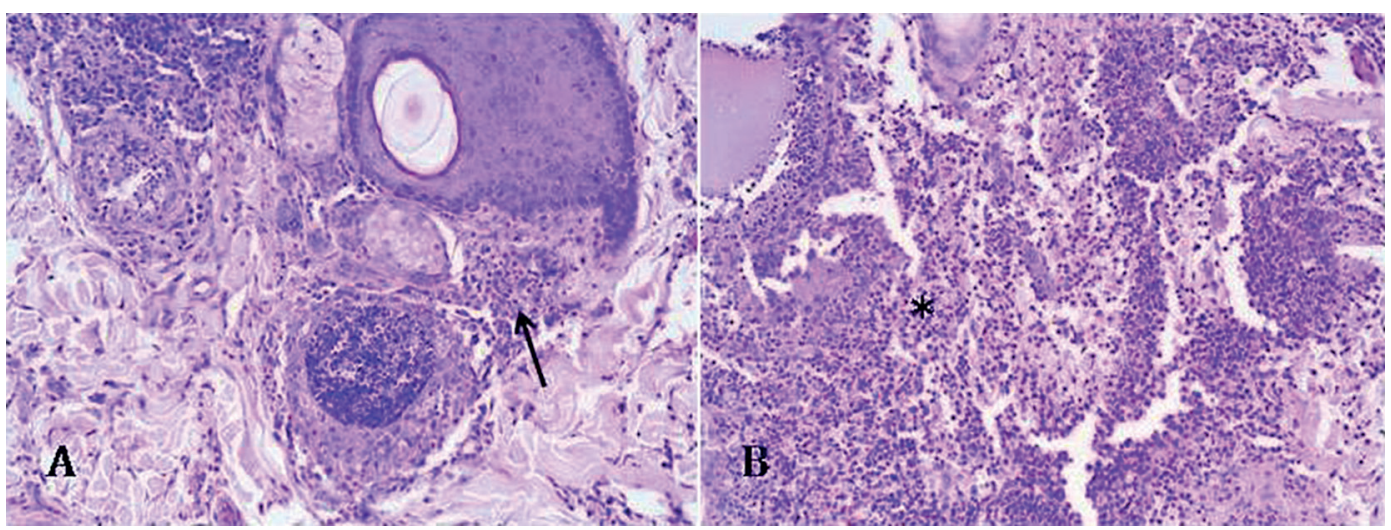

Fig.3, Hipersensibilidade alimentar canina. Pele. (A) Foliculite grave (seta). (B) Furunculose (asterisco). HE, obj.20x.

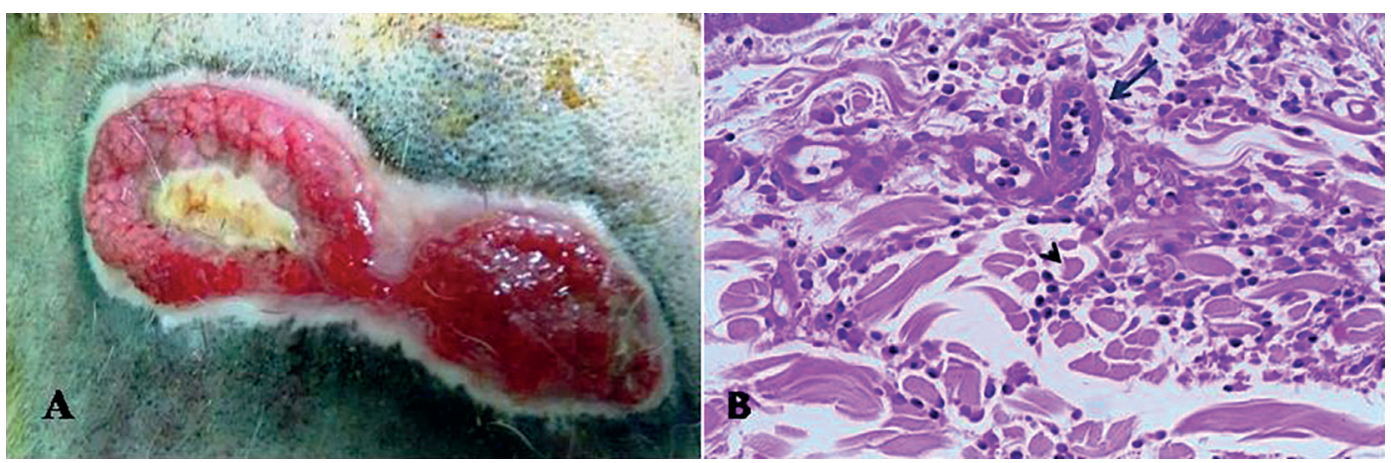

Fig.4. Dermatite alérgica de contato a lã de algodão. (A) Ulceração na pele com exsudato na região toracolombar. (B) Fragmento de pele com infiltrado inflamatório predominantemente eosinofílico com alguns mastócitos. Nota-se perivasculite com diapedese de eosinófilos (seta), associado à colagenólise (cabeça de seta). HE, obj.40x.

vado infiltrado inflamatório de células mononucleares que variou de leve a acentuado em todos os casos (Fig.3A,B). Além dos exames clínico, dermatológico e histopatológico. O diagnóstico de HA foi confirmado pela introdução da dieta de substituição (ração com proteína de cordeiro) associada à administração de predinisolona na dose de 1mg/ $\mathrm{kg} / \mathrm{pv}$ a cada 24 horas, por sete dias. A dieta de substituição foi emprega como única fonte de alimentação durante quinze dias. Após esse período o prurido cessou, as lesões cicatrizaram e as áreas hipotricóicas repilaram novamente.

A dermatite alérgica de contado (DAC) representando $8,33 \%(2 / 24)$ foi diagnosticada em dois cães sem raça defi- nida, sendo um macho $50 \%(1 / 2)$ e uma fêmea $50 \%(1 / 2)$ com oito e nove anos, respectivamente. Um caso resultou de dermatite alérgica de contato à lã de algodão e o outro ao contato com desinfetante para limpeza do ambiente onde o cão habitava. 0 animal que apresentou DAC à lã de algodão tinha como histórico clínico um ferimento ulcerado único com exsudato, durante uso de roupa cirúrgica de tecido de algodão. Foi realizada terapia tópica com Ganadol ${ }^{\circledR 7}$ por oito dias, não sendo observada a regressão da lesão, posteriormente realizou-se biópsia para exame histopatológico. Em que se observou hiperceratose (paraceratose), acantose, espongiose e presença de úlcera extensa na epiderme 
(Fig.4A). Na derme superficial foi observado edema e infiltrado inflamatório eosinofílico, com alguns mastócitos e macrófagos, colagenólise e paniculite (Fig.4B). Após sete dias da retirada da roupa cirúrgica a lesão recrediu e a região repilou. A DAC ao desinfetante acometeu um cão $50 \%$ (1/2) macho, SRD, de oito anos de idade, com histórico de lesões de pele a mais de um ano, associado a prurido localizado. 0 exame clínico dermatológico evidenciou a presença de comedões, colaretes epidérmicos, eritema, ulcerações, hipotricose e xerose epidérmica localizados nos flancos e abdome. No exame histopatológico os achados observados consistiram em hiperceratose, acantose, espongiose, edema, infiltrado inflamatório de células mononuclear localizado ao redor de vasos (perivasculite) e anexo (perianexite) e parte desse infiltrado se estendia para interface. A terapia instituída foi a base de predinisolona $1 \mathrm{mg} / \mathrm{kg} / \mathrm{pv}$ a cada 24 horas, por 7 dias e a retirada do desinfetante na limpeza do ambiente. Com regressão das lesões e do prurido após quinze dias.

A dermatite alérgica por picada de pulga (DAPP) acometeu um cão 4,17\% (1/24) macho, da raça Pastor Alemão de quinze anos de idade. 0 animal apresentava histórico de prurido localizado associado a ferimento ulcerado com exsudação. No exame clínico dermatológico foi observado alopecia, hiperpigmentação, eritema, ferimento exsudativo e presença de pulgas na região lombossacra. 0 exame citológico do exsudato evidenciou infiltrado inflamatório neutrofílico (piodermite superficial). No exame histopatológico da biópsia de pele verificou-se hiperceratose (paraceratose), acantose e espongiose moderada (Fig.5A,B), com presença de úlceras superficiais, edema, infiltrado inflamatório acentuado formado por mastócitos, eosinófilos, linfócitos e plasmócitos ao redor de vasos e anexos e dilatação de glândulas sudoríparas. Para o tratamento foi utilizado enrofloxacina $5 \mathrm{mg} / \mathrm{kg} / \mathrm{pv}$ a cada 24 horas, por sete dias, e Nitenpiram $57 \mathrm{mg}$ em dose única. Após quinze dias a lesão regrediu e o pelo voltou a crescer.

A dermatite por hipersensibilidade a medicamento (farmacodermia) foi diagnosticada em um cão 4,17\% (1/24) fêmea da raça Buldog Francês de um ano e meio de idade, com histórico de alopecia e prurido localizado que evoluiu para liquenificação, ulceração e exsudação. Na anamnese o proprietário informou que aplicou antibiótico (sulfametoxazol associado à trimetoprina) para tratar diarreia e lesão da pele surgiu poucos dias após a aplicação. No exame clínico dermatológico revelou alopecia, erosões, liquenificação e úlceras localizadas na região toracolombar. No exame histopatológico foram observados hiperceratose e espongiose moderada, acantólise acentuada (Fig.6A,B) e pústulas epidérmicas. Na derme foi observado edema leve, infiltrado inflamatório neutrofílico circundando vasos, glândulas sebáceas e glândulas sudoríparas. Foi realizada terapia a base

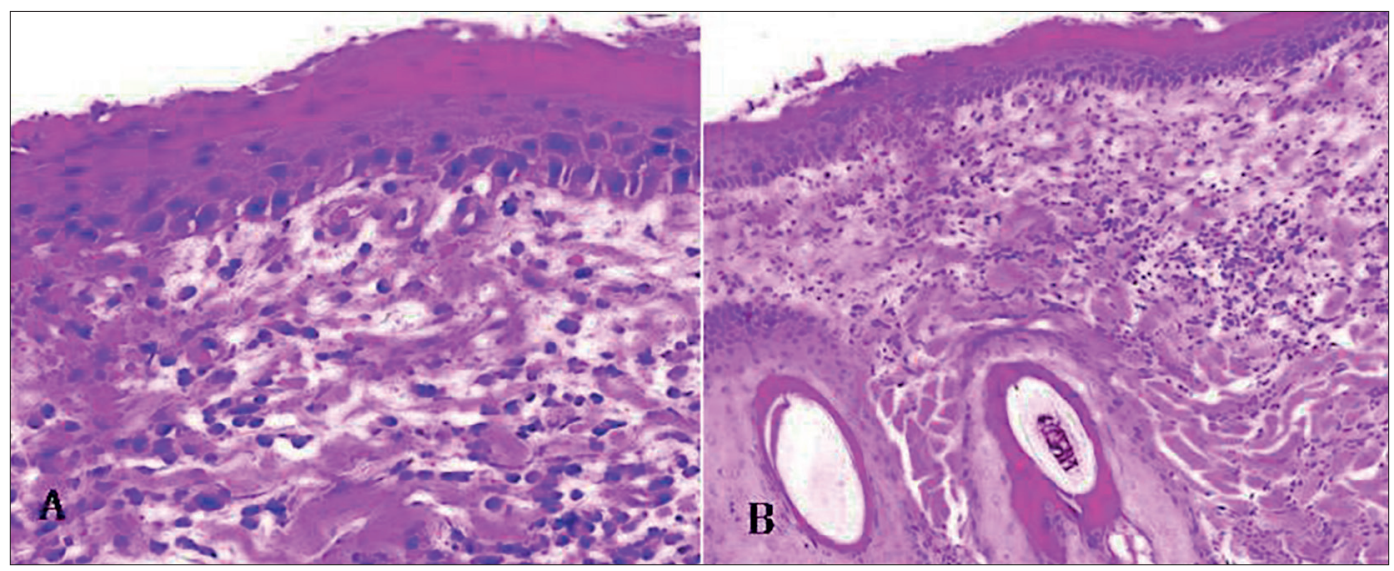

Fig.5. Dermatite alérgica por picada de pulga, cão. Pele. (A) Paraceratose na epiderme. HE, obj.40x. (B) Infiltrado inflamatório misto, composto por mastócitos, eosinófilos, linfócitos e plasmócitos ao redor de vasos sanguíneos da derme superficial. HE, obj.20x.

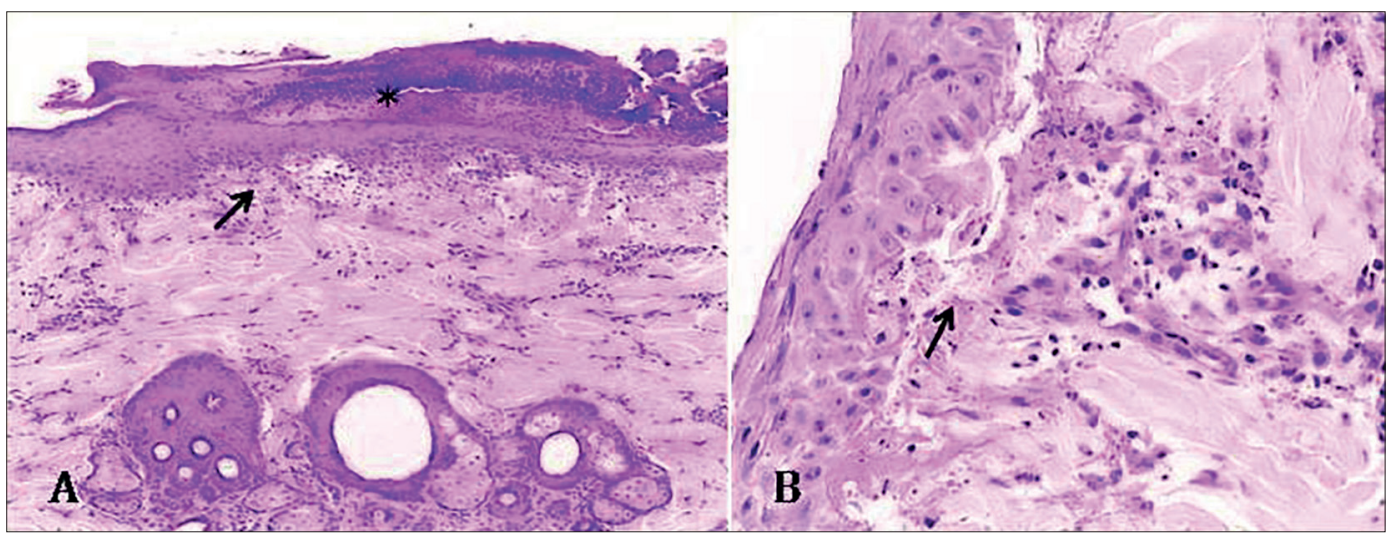

Fig.6. Dermatite por hipersensibilidade a medicamento, cão. Pele. (A) Pústula epidérmica (asterisco) e acantólise (seta). HE, obj.4x. (B) Detalhe da acantólise com discreta hemorragia e raras células inflamatórias neutrófilicas. HE, obj.40x. 
de predinisolona na dose de $1 \mathrm{mg} / \mathrm{kg} / \mathrm{pv}$ a cada 24 horas, por sete dias. Após cinco dias observou-se desaparecimento do prurido, e regressão do ferimento em dez dias.

\section{DISCUSSÃO}

O diagnóstico de dermatite alérgica foi realizado com base no histórico do animal, exame clínico geral e dermatológico, associado à avaliação dos padrões histopatológicos das lesões cutâneas. Outros estudos de doenças alérgicas demonstram que não há nenhum exame que substitua uma anamnese completa e um exame físico detalhado, mas quando o processo de doença não responde à terapia ou o diagnóstico clínico permanece duvidoso, a biópsia é uma ferramenta extremamente valiosa (Keeling et al. 2015). 0 exame histológico permitiu determinar a distribuição da lesão cutânea, tipo de resposta inflamatória e em quase todos os casos o padrão de lesão permitiu aferir o tempo de evolução da lesão.

O prurido observado nos cães com dermatite alérgica resultou em extensas áreas ulceração e infecções bacterianas e fúngicas, agravando o quadro clínico dermatológico. Apesar da piodermite e a dermatite fúngica serem consideradas diagnósticos diferenciais, essas lesões geralmente ocorrem como doenças secundárias na dermatite alérgica. Em geral esse conjunto de lesões causa repulsa fazendo com que os proprietários procurem atendimento veterinário (Souza et al, 2009).

Não foi observada predisposição quanto ao sexo, semelhante ao que é descrito na literatura por Gross et al. (2005). A idade dos cães apresentou uma grande variação neste estudo, essa característica também foi demonstrada por Souza et al. (2009) e Nagelstein (2010).

0 alto percentual de dermatite atópica corrobora com os dados publicados por Souza et al. (2009), em que representou $44,21 \%$ de todas as dermatites alérgicas em cães no município de Santa Maria, Rio Grande do Sul. Estudos realizados no Norte do Paraná por Cardoso et al. (2011), e em Cuiabá, Mato Grosso por Gasparetto et al. (2013), identificaram respectivamente, que os casos de atopia correspondiam a $27,78 \%$ e $10,5 \%$ dos casos de dermatopatias de origem alérgicas. Os critérios de Willemse, modificados por Pélaud et al. (1998) utilizaram uma combinação de histórico e sinais clínicos para o diagnóstico clínico de dermatite atópica que incluem, (1) prurido, que cessa com o uso de corticoides, (2) eritema das pinas, (3) pododermatite eritematosa cranial bilateral, (4) queilite e (5) apresentação dos primeiros sinais entre 6 meses e 3 anos de idade. No presente estudo esses critérios foram preenchidos, como a faixa etária e resposta ao uso de corticoides, a localização das lesões que prevaleceram nos membros torácicos, dorso e abdome. Embora os resultados tenham demonstrado que os cães com DA eram na grande maioria adultos, o que não significa que a doença não ocorra em cães jovens, visto que na maioria dos históricos clínicos os animais apresentavam o problema há vários meses ou anos. Nesse estudo chama atenção o diagnóstico da dermatite atópica em dois filhotes

\footnotetext{
${ }^{6}$ Dupraderme ${ }^{\circledR}$, Duprat Saúde Animal.

${ }^{7}$ Ganadol $^{\circledR}$, Zoetis Brasil.
}

de três e quatro meses de idade, diferentemente do que foi descrito por Medleau et al. (2009) e Cardoso et al. (2011), onde não verificaram a doença em caninos com menos de seis meses de idade. No presente estudo o acometimento de dois cães com menos de seis meses se deve a ocorrência da sensibilização primária que pode ser desencadeada dependendo dos alérgenos envolvidos, levando ao aparecimento dos sinais clínicos e as lesões da dermatite atópica antes dos seis meses de idade. Situação semelhante ao que é descrito por Scott et al. (2001) e Dethioux (2006), onde foi observado que os cães que nasciam na primavera, época de polinização, desenvolviam a DA com quatro meses de idade.

No presente estudo a DA foi mais frequente em cães de raça definida, o mesmo foi observado em um estudo no Norte do Paraná, onde $40 \%$ dos cães foram da raça Ihasa Apso (Cardoso et al. 2011). Estudos semelhantes também já foram realizados demonstrando predisposição por diferentes raças (Griffin \& DeBoer 2001, White 2003, Gross et al. 2009), enquanto Lucas (2007) diagnosticou a DA em cães SRDs. Neste estudo a DA foi mais frequente em cães machos do que nas fêmeas, mesmo assim não podemos afirmar que ocorre predileção por sexo, semelhante aos dados observados por Cardoso et al. (2011).

A hipersensibilidade alimentar foi observada em menor percentual por Souza et al. (2009) e Cardoso et al. (2011) que encontrou 11,11\%. Já Salzo \& Larsson (2009) observaram a prevalência mais próxima do encontrado nesse estudo com $17,1 \%$. 0 sinal clínico mais evidente nos seis casos foi o prurido associado a outros sinais clínicos. As lesões macroscópicas e a distribuição anatômica foram semelhantes às descritas por Medleau \& Hnilica (2009), Salzo \& Larsson (2009) e Rondelli et al. (2015).

No presente estudo a associação da corticoterapia e a dieta de substituição demonstram ser uma ferramenta tanto de diagnóstico quanto terapêutica, corroborando com os estudos de Salzo \& Larsson (2009) e Rondelli et al. (2015). Houve maior ocorrência de HA em cães sem raça definida, diferente do observado por Salzo \& Larsson (2009), que verificou maior frequência em cães da raça Poodle. Neste estudo as fêmeas foram mais acometidas, diferente do observado que obteve maior frequência em cães machos (Salzo \& Larsson 2009. Os animais acometidos tinham idade superior a dois anos, o que também foi descrito na literatura (Salzo \& Larsson 2009), porém de acordo com White (2003), a hipersensibilidade alimentar deve sempre constar do diagnóstico diferencial de prurido em cães jovens com menos de um ano.

Apesar da DAC ser relatada como rara ou infrequente (Medleau \& Hnilica 2009), foi possível diagnosticar dois casos, demonstrando que a doença ocorra com mais frequência e não é diagnosticada pelos clínicos e dermatologistas por falta de conhecimento, por ser uma doença de reação imunológica tardia ou por que a DAC se assemelha muito com outras dermatites alérgicas (Gross et al. 2005). Há também a resistência em realizar exame histopatológico por parte dos proprietários (Keeling et al. 2015). Na DAC a lã de algodão e na DAC ao desinfetante de limpeza, os achados foram semelhantes aos descritos por diferentes 
autores (Gross et al. 2005, Medleau \& Hnilica 2009, Hargis \& Ginn 2013). A retirada dos alérgenos e a boa resposta à corticoterapia corroboram com o descrito por Medleau \& Hnilica (2009).

No estudo de Souza et al. (2009) a DAPP foi a segunda dermatite alérgica mais diagnosticada, com $16,5 \%$, diferente do presente trabalho que diagnosticou $4,17 \%$, resultado esse que assemelha-se aos resultados obtidos por Gasparetto et al. (2013) e Cardoso et al. (2011) que encontraram $4,8 \%$ e $4,29 \%$, respectivamente. Gross et al. (2005) descreveram lesões macroscópicas e microscópicas semelhantes com exceção da dilatação de glândula sudoríparas. Embora o animal acometido não apresentasse características da DAPP, o diagnóstico só foi possível através da utilização de vários meios de diagnósticos. Na DAPP as lesões caracterizam-se mais por presença de áreas hipotricóicas (Scott et al. 2001, Medleau \& Hinilica 2009), diferente do que ocorreu do cão do presente estudo que apresentou ulcerações e liquenificação. Apesar de a DAPP ter acometido apenas um cão de raça pura não é descrito predisposição racial ou sexual. Não foi observada sazonalidade no presente estudo, apesar desta característica ser descrita na literatura (Scott et al. 2001, Medleau \& Hnilica 2009).

No presente estudo as lesões apresentadas são secundárias ao autotrauma resultante do prurido e a distribuição localizada provavelmente se deve ao fato da pequena quantidade de pulgas encontrada no animal.

A literatura estima que a prevalência de casos de farmacodermia seja ainda menor do que o percentual do presente estudo, respondendo por aproximadamente $2 \%$ dos casos de doenças alérgicas da pele de cães (Scott et al. 2001). As lesões foram semelhantes às descritas por diferentes autores (Medleau et al. 2009, Silva et al. 2013, Hargis \& Ginn 2013), entretanto, Trapp et al. (2005) descreveram lesões necróticas ulcerativas com desprendimento da pele após cinco dias de aplicação de sulfonamida associada a trimetoprina numa dose $50 \%$ a maior do que a dose terapêutica recomendada. As sulfonamidas, especialmente aquelas potencializadas pelo trimetoprina, são mais comumente identificadas por produzirem reações em cães e gatos (Scott et al. 2001). Suspeita-se também de predisposição genética a reações cutâneas (hipersensibilidade tipo III) com o uso de sulfadiazinas em cães da raça Dobermann Pinscher (Giger et al. 1985). Isso não foi possível avaliar no presente estudo, pois a doença só foi diagnosticada em apenas um caso. Apesar de não está claro o motivo que algumas pessoas ou animais tenham intolerância as sulfonamidas, existe duas hipóteses, a primeira é que ligações covalentes entre as proteínas do indivíduo e os metabólitos da sulfonamidas como a hidroxilamina e os compostos nitrosos podem induzir respostas imunes específicas adversas (Choquet et al. 2002) e a outra hipótese é a ativação dos linfócitos T durante a bioativação do fármaco, resultando na estimulação da resposta imune (Naisbitt 2004, Trepanier 2004).

\section{CONCLUSÕES}

Os resultados desse estudo demonstram que as dermatites alérgicas são frequentes e que podem estar associadas a diferentes causas.
Observou-se maior ocorrência de dermatite atópica, seguidas de dermatite por hipersensibilidade alimentar, dermatite alérgica de contato, hipersensibilidade a fármacos (farmacodermia) e dermatite por hipersensibilidade a picada de pulgas.

O prurido foi o sinal clínico mais comum em todas as dermatites sem padrão de sazonalidade. 0 exame histopatológico associado à anamnese, histórico clínico, exames clínicos e dermatológicos é uma importante ferramenta para o diagnóstico das dermatites alérgicas.

\section{REFERÊNCIAS}

Cardoso M.J.L., Machado L.H.A., Melussi M., Zamarian T.P., Carnielli C.M. \& José Júnior C.M.F. 2011. Dermatopatias em cães: revisão de 257 casos. Arch. Vet. Sci. 16:66-74.

Choquet K.G., Vial T. \& Descotes J. 2002. Allergic adverse reactions to sulfonamides. Curr. Allergy Asthma Rep. 2:16-25.

Conceição L.G., Loures F.H., Clemente J.T. \& Fabris V.E. 2004. Biópsia e histopatologia de pele: um valioso recurso diagnóstico na dermatologia. I. Revisão. Clín. Vet. 51:36-44.

Dethioux F.A. 2006. Dermatite atópica canina: um desafio para o clínico. Waltham Focus, Aimargues: Royal Canin. 1:7-56.

Gasparetto N.D., Trevisan Y.P.A., Almeida N.B., Neves R.C.S.M., Almeida A.B.P.F., Dutra V., Colodel E.M. \& Sousa V. R.F. 2013. Prevalência das doenças de pele não neoplásicas em cães no município de Cuiabá, Mato Grosso. Pesq. Vet. Bras. 33(3):359-362.

Giger U., Werner L.L., Milichamp N.J. \& Gornan N.T. 1985. Sulfadiazine-induced allergy in six Doberman Pinschers. J. Am. Vet. Med. Assoc. 186: 479-484.

Griffin C.E. \& DeBoer D.J. 2001. The ACVD task force on canine atopic dermatitis (XIV): clinical manifestations of canine atopic dermatitis. Vet. Immunol. Immunopathol. 8:255-269.

Gross T.L., Ihrke P.J., Walder E.J. \& Affolter V.K. 2005. Skin diseases of the dog and cat. Clinical and histopathologic diagnosis. 2nd ed. Blackwell, Oxford. 932p.

Halliwell R.E.W. 2009. Allergic skin diseases in dogs and cats: na introduction. EJCAP 19:209-211.

Hargis A.M. \& Ginn P.E. 2013. 0 tegumento, p.975-1186. In: Zachary J.F., McGavin M.D. (Eds), Bases da Patologia em Veterinária. 5a ed. Elsevier, Rio de Janeiro.

Keeling B.H., Gavino A.C.P. \& Gavino A.C.P. 2015. Skin Biopsy, the Allergists Tool: how to interpret a report. Allergic Skin Diseases, Curr Allergy Asthma Rep. 15:62.

Leung D.Y. 1995. Atopic dermatitis: the skin as a Windows in to the pathogenesis of chronic allergic diseases. J. Clin. Immunol. 96:302-319.

Lucas R. 2007. Diagnóstico diferencial das principais dermatopatias alérgicas em cães. Nosso Clínico 10:6-18.

Marsella R. \& Olivry T. 2001. The ACVD task force on canine atopic dermatitis (VII): mediadores cutaneous inflammation. Vet. Immunol. Immunopathol. 81:205-213.

Medleau L. \& Hnilica K.A. 2009. Dermatologia de Pequenos Animais: atlas

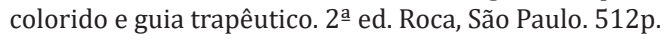

Naisbitt D.J. 2004. Drug hypersensitivity reactions in skin: understanding mechanisms and the development of diagnostic and predictive tests. BTS Annual Congress 194:179-196.

Nagelstein A.F. 2010. Patogenia da dermatite atópica em cães. Trabalho de Conclusão do Curso de Pós-Graduação Lato Sensu, Especialização em Dermatologia de animais de companhia. Unigran, Dourados. 38p.

Pélaud P., Guaguére Alhaidari N., Faivre D., Heripret D. \& Gayerie A. 1998. Reevaluation os diagnostic criteria of canine atopic dermatitis. Revta Med. Vet. 149:1057-1064.

Rondelli M.C.H., Oliveira M.C.C., Silva F.L., Palácios Junior R.J.G., Peixoto M.C., Carciofi A.C. \& Tinucci-CostaI M.A. 2015. Retrospective study of 
canine cutaneous food allergy at a Veterinary Teaching Hospital from Jaboticabal, São Paulo, Brazil. Ciência Rural 45:1819-1825.

Scott D.W., Miller D.H. \& Griffin C.E. 2001. Muller and Kirk's Small Animal Dermatology. 6th ed. W.B. Saunders, Philadelphia. 1528p.

Salzo P.S. \& Larsson C.E. 2009. Hipersensibilidade alimentar em cães. Arq. Bras. Med. Vet. Zootec. 61:598-605.

Silva A.P., Schmidt C. \& Souza T.M. 2013. Reação a fármaco semelhante ao pênfigo foliáceo em um cão. Revta Educ. Cont. Dermat. Alerg. Vet. 2:218-222.

Souza T.M., Fighera R.A., Schmidt C., Requias A.H., Brum J.S., Martins T.B. \& Barros C.S.L. 2009. Prevalência das dermatopatias não-tumorais em cães do município de Santa Maria, Rio Grande do Sul (2005-2008). Pesq. Vet. Bras. 29:157-162.

Trapp S.M., Haddad Neta J., Okano W., Juliani L.C. \& Sturion D.J. 2005. Farmacodermía asociada a reacciones sistémicas em uno perro Pinscher Miniatura medicado com asociación de trimetoprin y sulfadiazina. Arq. Ciênc. Vet. Zool. 8:79-85.

Trepanier L.A. 2004. Idiosyncratic toxicity associated with potentiated sulfonamides in the dog. J. Vet. Pharmacol. Therap. 27:129-138.

White P.D. 2003. Atopia, p.372-380. In: Bichard S.J. \& Sherding R.G. (Eds), Manual Sauders Clínica de Pequenos Animais. $2^{\underline{a}}$ ed. Roca, São Paulo. 